
CREST Working Paper

A Fresh Look at the Rotten Kid Theorem ---and Other Household Mysteries

Ted Bergstrom

November, 1986

Number $87-5$

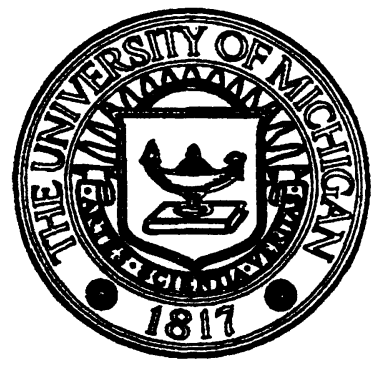

DEPARTMENT OF ECONOMICS University of Michigan Ann Arbor, Michigan 48109

The Sumner and Laura Foster Library 



\title{
A Fresh Look at the Rotten Kid Theorem -and Other Household Mysteries
}

\author{
by
}

Ted Bergstrom

University of Michigan

November, 1986

Current version: January 8, 1987 



\section{A Fresh Look at the Rotten Kid Theorem \\ - and Other Household Mysteries \\ Ted Bergstrom}

\section{The Rotten Kid Theorem}

The famous "Coase Theorem" has a younger sibling-also from the streets of Chicagocalled the "Rotten Kid Theorem". The Rotten Kid Theorem, seems to have been first stated by Gary Becker in his 1974 article, "A Theory of Social Interactions" and continues to play a lively role in discussions of the theory of the family. ${ }^{1}$ The idea of the theorem, as described in the 1974 article is this. If a family has a head who

“... cares sufficiently about all other members to transfer general resources to them, then redistribution of income among members of the household would not affect the consumption of any of them, so long as the head continues to contribute to all... The major and somewhat unexpected conclusion is that if a head exists, other members also are motivated to maximize family income and consumption, even if their welfare depends on their own consumption alone."

In his 1981 book, A Treatise on the Family, Becker restates the Rotten Kid theorem like this:

"Each beneficiary, no matter how selfish, maximizes the family income of his benefactor and thereby internalizes all effects of his actions on other beneficiaries." (p. 183)

If it is generally correct, The Rotten Kid Theorem must be one of the most remarkable and important results in the theory of incentives. For it tells us that a sufficiently benevolent household head would automatically internalize all of the external effects that family members have on each other. Benevolent parents of intelligent, though selfish, children can breathe easier. In the family there will be no free-rider problems or principal agent problems. Elaborate incentive schemes and detection devices are unnecessary. All that is needed is to explain the Rotten Kid Theorem to each family member and they will all (except possibly for a few irrational lapses) behave in the common interest. Not only would this be remarkable good news for parents, it would suggest a promising way of avoiding the incentive problems that bedevil firms and other social organizations. Shouldn't it be possible be to find group incentive structures similar to those of families with benevolent heads?

This paper argues that the Rotten Kid Theorem applies less generally than has sometimes been believed. But the news is not all bad. The theorem remains true for a rather restrictive, but still interesting, class of special cases of preferences and technologies. As with all theorems that have strong and interesting conclusions, it is worthwhile to find the

I Becker says that he owes the theorem's colorful name to "the Barro family". Becker is not explicit about whether this family inspired or merely suggested that name. 
limits of generality in which the Rotten Kid Theorem applies and to show examples where its conclusion holds and where it fails.

Becker's formal model and the proof of his theorem are clearly stated in his 1974 paper. The story is this. Suppose that there is one family member, the household head whose benevolence toward the other family members is such that, given the current distribution of wealth among family members, he chooses voluntarily to give income to all of the others. There is a single consumption good and $X_{i}$ denotes the amount of consumption by family member $i$. Suppose that all family members except the head of the household are selfish and interested only in their own consumptions. The head of the household is altruistic and his utility depends positively on the consumption of each household member. Therefore one can write the head's utility as

$$
U_{i}\left(X_{1}, \ldots, X_{n}\right) .
$$

Let $I_{i}$ be the income of family member $i$ before any intrafamily transfers occur. Total expenditures on consumption for family members must satisfy

$$
\sum_{i} X_{i}=\sum_{i} I_{i} .
$$

If the head of the household is making transfers of income to all other household members, then after the transfers are made, the family income distribution will be the income distribution that maximizes the household head's utility subject to the constraint that total family consumption equal total family income. Therefore the consumption level of each family member is determined by choosing a distribution of income, $\left(X_{1}, \ldots X_{n}\right)$, that maximizes the utility function, (RK1), subject to the budget constraint, (RK2). This is like a standard problem in consumer theory in which the "goods", $X_{i}$, have prices of unity and income is $\Sigma I_{i}$. Given the reasonable assumption that the $X_{i}$ 's are all "normal goods" for the head of the household, it follows that each $X_{i}$ is a uniquely determined monotonic increasing function of total family income. Therefore if any of the selfish children has an opportunity to increase total family income, even if it is at the cost of reducing his own pre-transfer income, he will choose to do so because the only way to increase one's consumption after gifts from the head of the household are accounted for is to increase family income. This proves the Rotten Kid Theorem.

\section{Lazy Rotten Kids Who Act Rotten}

It is worth noticing, but not very surprising that the Rotten Kid Theorem fails to apply when there is asymmetric information. To see the problem, suppose that the income of each family member, $i$, is a function $I_{i}\left(Y_{i}\right)$ where $Y_{i}$ is an index of how hard $i$ works. Let each child's utility depend on his consumption of the one produced good and on his consumption of leisure, where leisure of $i$ is measured as $1-Y_{i}$. Suppose that the parent is able to observe incomes but not individual effort levels and that he chooses an allocation of consumption in the family to maximize the utility function (RK1) subject to the constraint (RK2). Then a selfish child will have insufficient incentive to work since he will not receive the marginal product of an extra bit of effort but only this marginal product times the household head's marginal propensity to spend on him. 
But suppose that the head of the household is able to observe both the incomes and the levels of work effort by his children, and suppose that the head's utility depends on the utilities of his children and not just on their consumptions. Then will the Rotten Kid Theorem hold? If the head of the household is only able to give gifts of money and does not direct the distribution of leisure, the answer is: "In general, no." Here is an example that shows why. Suppose that the head of the household has two children (named 1 and 2) and that the utility function of each child $i$ is a function:

$$
U_{i}=X_{i}\left(1-Y_{i}\right)
$$

where $Y_{i}$ is $i$ 's work effort. To simplify calculations, suppose that the head doesn't work or consume himself, but he has an income $I_{0}$ and his utility function is:

$$
\begin{aligned}
U_{0} & =U_{1}^{1 / 2}+U_{2}^{1 / 2} \\
& =X_{1}^{1 / 2}\left(1-Y_{1}\right)^{1 / 2}+X_{2}^{1 / 2}\left(1-Y_{2}\right)^{1 / 2}
\end{aligned}
$$

Suppose that each child earns an income $I_{i}=w Y_{i}$ and that the head of the household is able to observe the work effort of each child. The head will make gifts to his children in such a way that their consumptions maximize (RK4) subject to the constraints:

$$
X_{1}+X_{2}=I_{0}+w Y_{1}+w Y_{2}
$$

and

$$
X_{i}>I_{i} \quad \text { for } i=1,2 .
$$

The latter constraint reflects an institutional restriction that forbids the household head to confiscate income from his children. Some simple computations show that for the particular utility functions (RK3) and (RK4), the maximum of (RK4) subject to (RK5) occurs when $X_{1} / X_{2}=\left(1-Y_{1}\right)^{2} /\left(1-Y_{2}\right)^{2}$. Using this fact and the budget equation (RK5) one can explicitly calculate each child's consumption as a function of his own work effort and of the other child's work effort. But all that one really needs to notice here is that each child's share of total family income is a decreasing function of his work effort. Therefore the incentive problem is even worse in this example than in the case where the household head did not observe individual effort.

It is true that the head of the household could devise a better incentive scheme for his family. For example, he might pay "wages" for work effort by family members. But the Rotten Kid Theorem does not allow us to claim that household incentive problems are solved automatically. Later we will show that even if wages are needed to give proper incentives to work, the Rotten Kid theorem may still have an interesting application to other household externalities. But first let us look at another example.

\section{The Case of the Controversial Nightlight}

Becker (1974), (1982) offers another provocative "application" of the Rotten Kid Theorem. This example (slightly embellished) is the case of a husband who wishes to read at night although the light bothers his wife. As the plot develops, the husband loves his wife and makes gifts of consumption goods to her, while the wife is entirely selfish. One day while the husband is away at work, an electrician calls on the wife and offers to disconnect the 
nightlight in such a way that the husband would think it an accident and would not be able to use it again. The wife, though she is selfish and though she dislikes the nightlight, ponders whether she should accept the electrician's offer. According to Becker, she should refuse. He reasons that if she has the nightlight disconnected, the husband will be worse off. Even though he will not blame her for the loss of the nightlight, the effect is like a loss in family income. If her utility is a "normal good" for him, the loss of family income will lead the husband to reduce his gifts of consumption goods to her so that her utility after the nightlight is disconnected is lower than it had been before. Becker explains his reasoning as follows.

"Perhaps a surprising implication of this analysis is that both are made better off when an altruist or his selfish beneficiary decides to eat with his fingers or read in bed. Since the utility of the altruist would be raised, he would increase his contribution to her by more than her initial harm from his actions or reduce his contribution by more than his initial harm from her actions." Treatise on the Family (page 179)

Is Becker right? It is instructive to model this case more explicitly, using the apparatus of public goods theory. Let $X_{h}$ be goods consumption of the husband, let $X_{w}$ be goods consumption of the wife, let $I$ be family income, and let $Y$ be the number of hours that the husband spends reading in bed. Following Becker, let us suppose that the husband is altruistic and the wife is selfish. Iet us also suppose that the husband's utility can be represented in the form $U_{h}\left(u_{h}\left(X_{h}, Y\right), u_{w}\left(X_{w}, Y\right)\right)$ where the wife's utility function is $u_{w}\left(X_{w}, Y\right)$. In accordance with Becker's story, $u_{w}$ is an increasing function of $X_{w}$ and a decreasing function of $Y$. The function $u_{h}\left(X_{h}, Y\right)$ is an aggregator function representing the husband's "private preferences" over alternative combinations of nightlight and goods consumption for himself, holding constant the wife's utility. The function $U_{h}(.,$.$) is an$ increasing function of its two arguments, $u_{h}$ and $u_{w}$. The husband chooses the distribution of private consumption in the family subject to the family budget constraint.

Let the utility functions take the special form:

$$
U_{h}\left(u_{h}, u_{w}\right)=u_{h} u_{w}^{a}
$$

where $0<a<1$ and where

$$
\begin{gathered}
u_{h}\left(X_{h}, Y\right)=X_{h}(Y+1) \text { and } \\
u_{w}\left(X_{w}, Y\right)=X_{w} e^{-Y} .
\end{gathered}
$$

This special case incorporates all of the qualitative features of Becker's discussion and displays strictly convex preferences for both people. One can substitute (N2) and (N3) into (N1) to write the husband's utility in terms of the decision variables, $X_{h}, X_{w}$, and $Y$. This yields

$$
U_{h}=X_{h} X_{w}^{a}(Y+1) e^{-a Y}
$$

If the husband determines the division of the family income between his wife's consumption and his own, he would seek to maximize (N1) subject to the constraint

$$
X_{h}+X_{w}=I \text {. }
$$


Simple calculations show that in this example, the husband would choose to divide income so that $X_{w}=a I /(1+a)$. This means that his choice of how to divide the family income is completely independent of the level of $Y$. If the husband can choose $Y$ he will choose $Y=$ $\frac{1}{n}-1>0$. On the other hand, since the wife's allowance of private goods is independent of $Y$, and since her utility is a decreasing function of $Y$, she would choose $Y=0$ if she had her choice in the matter.

In this example, the outcome when the wife chooses the amount of reading is not Pareto optimal while the outcome when the altruistic husband chooses every thing must be Pareto optimal. Nevertheless the wife is better off when she chooses $Y$ than when he does. Of course the husband could bribe the wife to allow him to read, but there is not an automatic incentive for the wife to choose a Pareto optimal amount of public good without an explicit bargain being struck.

\section{Where did the Rotten Kid Theorem go Wrong?}

In the last two examples, the Rotten Kid Theorem does not seem to apply, at least in a straightforward way. Why does this happen? In each of the examples, the trouble arose when a second commodity appeared. In the Case of the Lazy Rotten Kids, it was the introduction of the private commodity, work effort, that caused the trouble. In the Case of the Controversial Nightlight, it was the introduction of a public good, the nightlight. Becker's proof of the Rotten Kid. Theorem is correct, but notice that it explicitly assumes that there is only one commodity. Ilis analytical discussion surrounding the Case of the Nightlight suggests that the Rotten Kid Theorem extends to this case because the loss of the nightlight is equivalent to a certain loss in family income. This step in the argument, though it seems very reasonable, is incorrect.

A good way to see where the argument goes wrong is to look at the "utility possibility frontier" depicting the locus of feasible combinations of $u_{h}$ and $u_{w}$ that can be achieved by redistributing income, conditional on a given choice of $Y$. From equations (N2), (N3), and (N5), it follows that this frontier is described by the equation

$$
\frac{u_{h}}{Y+1}+u_{w} e^{Y}=I
$$

In case $Y=0$, one sees by substitution into (N6) that the equation for the utility possibility frontier is just $u_{h}+u_{w}=I$. In Figure 1 , below, this frontier is the line $A B$. In case $Y=1$, the utility possibility frontier becomes $u_{h} / 2+u_{w} e=I$. This frontier is depicted by the line $C D$. Notice that a change in $Y$ changes the slope as well as the position of the utility possibility frontier. Suppose that the husband is not able to choose $Y$, but it is chosen by someone else. Then when he chooses the family distribution of income, he is choosing a point on the utility possibility frontier that is conditional on that choice of $Y$. On Figure 1 , one can draw his indifference curves, which are just the level sets of the utility function (N1). Formally, the husband's choice problem is to choose $u_{h}$ and $u_{w}$ to maximize (N1) subject to (N5). Since (N1) is of the Cobb-Douglas form, he will choose

$$
u_{h}=\frac{Y+1}{1+a} \text { and } u_{w}=\frac{a e^{-Y}}{1+a} \text {. }
$$

As is seen from (N5), the smaller $Y$ is in this example, the "cheaper" it is to supply $u_{w}$ and the more "expensive" it is to supply $u_{h}$. Consequently, as (N7) shows, the smaller $Y$ is, the more $u_{w}$ the husband will choose. The selfish wife will therefore want $Y$ to be as small as possible. 


\section{Can the Rottén Kid Theorem be Rehabilitated?}

The key to when the Rotten Kid Theorem applies is the existence of transferable utility. The term "transferable utility" appears to have originated in game theory, but the idea that it represents is a familiar one to all economists. There is transferable utility in an $n$ person economy if there exists some utility representation of individual preferences such that for this representation, the utility possibility frontier is a set of the form

$$
\left.\left\{u_{1}, \ldots, u_{n}\right) \geq\left(\bar{u}_{1}, \ldots, \bar{u}_{n}\right) \mid \sum_{i} u_{i}=I\right\}
$$

for some $I$ and some $\left(\bar{u}_{1}, \ldots, \bar{u}_{n}\right)$. Geometrically, this means that the "utility possibility frontier" is a simplex. Whenever the utility possibility frontier is a simplex, it is natural to speak of there being transferable utility because starting from a Pareto optimum, any "transfer of utilities" that preserves the sum of utilities (and does not lower anyone's utility below the minimal amount $\bar{u}_{i}$ ) represents another feasible and Pareto optimal distribution.

Becker's proof of the Rotten Kid Theorem works for a case where the utility possibility frontier is a simplex and where the actions of the kids simply move the boundary of the simplex inward or outward in parallel fashion as in figure 2. The role of the benevolent head of the household is to choose a point on the utility possibility frontier that is determined by the actions of the kids. So long as the head of the household is benevolent and treats the utility of each of the kids as a normal good, all of the kids will agree that an outward shift of the utility possibility frontier is a "good thing" and an inward shift is a "bad thing". It is worth noticing that choice by a benevolent household head is not the only household choice mechanism that has this property. For example, another story consistent with everyone benefiting from a parallel outward shift in the family utility possibility frontier would be that the outcome turns out to be a Nash bargaining solution in which everyone with any bargaining power is nonmalevolent and someone with bargaining power is actually benevolent.

This discussion will establish conditions under which the utility possibility frontier is a simplex that shifts in a parallel fashion in response to family members' actions. Whenever this is the case, the Rotten Kid Theorem applies and furthermore, many other houschold decision mechanisms besides the benevolent dictatorship of a household head will lead to "automatic" meshing of incentives and Pareto efficient behavior by all family members. ${ }^{2}$ We will work our way from quite special and trivial cases to more general and subtle results. One reason for doing this is to help relate the general results to familiar special cases as well as to motivate and build intuition. Impatient readers may wish to skip ahead to these general results.

\section{Rotten Kids who Only Care About One Thing}

The simplest example of transferable utility is the case where individual utilities depend only on the consumption of a single private good, which is freely transferable among

2 An organization, all of whose members seek to maximize the same objective function, is known in the incentives literature as a team (Marschak and Radner (19??). Team theory is concerned with the question of how a team can economize on information by decentralizing decision making. This paper is concerned with when a family act as a team and not with the informational problems that arise even when all members have a common goal. 
consumers and which is available in fixed supply. This case can be used to establish the simplest version of the Rotten Kid Theorem. Consider a household with $n$ persons. Person 1 is the household head and each household member, $i$, other than the household head is entirely selfish and cares only about $i$ 's own consumption. The utility function, $u_{i}\left(X_{i}\right)=X_{i}$, represents the "private preferences" of individual $i$. In this simple model, their own private preferences are all that concern the selfish household members. But the head of the household, who cares about the well-being of each family member, has a utility function, $U_{i}\left(u_{1}, \ldots, u_{n}\right)=U_{i}\left(X_{1}, \ldots, X_{n}\right)$, that reflects his valuation of each person's utility. Each member of the family is able to perform a number of different activities that may earn money and may affect the earnings of other family members. Let $Y_{i}$ be the vector of such activities undertaken by $i$ and let $Y=\left(Y_{1}, \ldots, Y_{n}\right)$. Then income of family member $i$ is a function $I_{i}(Y)$. Total family income is $I(Y)=\cdot \sum_{i} I_{i}(Y)$. The set of allocations of private goods that are feasible if $Y$ is the vector of family activities is $\left.\left.\left\{\left(X_{1}, \ldots, X_{n}\right) \geq 0\right\} \mid \sum_{i} X_{i}=I(Y)\right)\right\}$. The utility possibility frontier, expressing the feasible combinations of $u_{i}$ 's, is the set $\left\{\left(u_{1}, \ldots, u_{n}\right) \geq 0 \mid \sum_{i} u_{i}=I(Y)\right\}$. Any increase in $I(Y)$ will lead to a parallel expansion of the utility possibility frontier. Therefore if parallel expansions of the utility possibility frontier benefit all family members, then each $i$ will wish to choose $Y_{i}$ to make total family income, $I(Y)$, as large as possible.

\section{Quasilinear Rotten Kids}

The next simplest class of examples that exhibit transferable utility are those with quasilinear utility. Let the setup be as in the previous example except that the vector of activities $Y_{i}$ chosen by family member $i$ may influence $i$ 's utility as well as family income. We will also allow the possibility thal some of the activities chosen by one family member may annoy or amuse other family members. But we assume that each person's private preferences are representable by a utility function of the quasilinear form, $u_{i}\left(X_{i}, Y\right)=X_{i}+f_{i}(Y)$ where $Y$ is a concave function of the vector $Y$ of activities chosen by family members. The set of allocations of $X$ that is possible if $Y$ is the vector of family activities is again $\left.\left\{\left(X_{1}, \ldots, X_{n}\right) \geq 0 \mid \sum_{i} X_{i}=I(Y)\right)\right\}$.

Since $X_{i}=u_{i}-f_{i}(Y)$, it follows that the utility possibility frontier is just the set,

$$
\left\{\left(u_{1}, \ldots, u_{n}\right) \geq\left(\bar{u}_{1}, \ldots, \bar{u}_{n}\right) \mid \sum_{i} u_{i}=I(Y)+\sum_{i} f_{i}(Y)\right\}
$$

where $\bar{u}_{i}=f_{i}(Y)$ for each $i$.

Typical utility possibility sets for different choices of $Y$ are illustrated in figure 3 . Changes in $Y$ that increase $I(Y)+\sum_{i} f_{i}(Y)$ cause a parallel outward shift of the utility possibility frontier. Therefore the direct effect of the activities $Y$ on utilities influence the utility possibility frontier in much the same way as if they were changing family income. The appropriate concept of "family income" becomes $I(Y)+\sum_{i} f_{i}(Y)$ rather than just $I(Y)$. There is one other difference between this model and the model of the last section where only income influences utility. This difference is that the minimal utility, $\bar{u}_{i}$, that can be assigned to any household member when the vector of household activities is $Y$ will be $f_{i}(Y)$ rather than 0 . This minimal utility is achieved if $i$ receives no $X_{i}$ at all. In this discussion we will be concerned with household heads (or other family mechanisms) that assign positive $X_{i}$ to each family member, so that these boundaries need not be of serious concern to us. 


\section{More Generally Rotten Kids}

The assumption of quasilinear utility is very restrictive. With quasilinear utility, the money value that a person puts on any vector of actions, $Y$, is entirely independent of that person's consumption of the private good $X$. This does not seem to be a reasonable assumption if one of the components of $Y$ is work effort or if some of the components of $Y$ involve consumption of household public goods for which the income elasticity of demand is not zero. All too frequently in the economic literature, one finds quasilinear utility described as "additively separable preferences". The authors should know better. Quasilinear utility is, of course, additively separable, but the assumption of quasilinearity is much stronger than the assumption of additive separability. In fact the utility functions that we used in our counterexamples with Lazy Rotten Kids and with Nightlights all have additively separable utility functions for all members of the family. ${ }^{3}$ Evidently, then, additive separability does not guarantee transferable utility.

It turns out that there is transferable utility in a considerably broader class of cases than the quasilinear case. Bergstrom and Cornes (1983) showed that there is transferable utility in a model with public and private goods precisely when the Pareto optimal amount of public goods is independent of wealth distribution. They were able to show that a general necessary and sufficient condition for this to happen is that preferences are representable by a utility function that is dual to the Gorman polar form (Gorman (1961). This means that the utility function of every consumer $i$ is of the form

$$
u_{i}\left(X_{i}, Y\right)=A(Y) X_{i}+B_{i}(Y) .
$$

where $Y$ is the vector of public goods and $X_{i}$ is private goods consumption by $i_{.4}$

Suppose that the private preferences of all household members are representable by utility functions of the form (T3), where $X_{i}$ is consumption of a private consumption good by member $i$ of the household and where $Y$ is a vector of activities by members of the household. Suppose that, given the level of $Y$, the set of possible allocations of $X$ is just

$$
\left\{\left(X_{1}, \ldots, X_{n}\right) \geq 0 \mid \sum_{i} X_{i}=I(Y)\right\}
$$

Adding the expressions (T3) for all $i$, and taking into account (T4), one finds that the utility possibility frontier for this class of utility functions is

$$
\left\{\left(u_{1}, \ldots, u_{n}\right) \geq\left(\bar{u}_{1}, \ldots, \bar{u}_{n}\right) \mid \sum_{i} u_{i}=A(Y) I(Y)+\sum_{i} B_{i}(Y)\right.
$$

where $\bar{u}_{i}=B_{i}(Y)$. It is apparent from (T5) that there is transferable utility for fixed $Y$ and that changes in $Y$ lead to parallel outward shifts of the utility possibility frontier just as in

3 Cobb-Douglas utility is additively separable. To see this, just make a monotone transform by taking the $\log$ of the utility function.

4 Bergstrom and Cornes also show that if $A(Y)>0$ for all $Y$ in the domain, then a function of the form (T3) will be quasi-concave if and only if the function $\alpha(Y)=1 / A(Y)$ is a convex function and the function $\beta(Y)=B(Y) / A(Y)$ is concave in $Y$. 
the case of transferable utility. Therefore, if parallel outward shifts of the utility possibility frontier benefit everyone, as in the story of the Rotten Kid Theorem, all household members would agree that $Y$ should be selected so as to maximize $A(Y) I(Y)+\sum_{i} B_{i}(Y)$.

How much of a generalization is (T3) over the quasilinear case? In the special case where $A(Y)$ is constant, (T3) is just the quasilinear case. In the case where $B_{i}(Y)$ is a constant, (T3) represents preferences that are identical among consumers and CobbDouglas in $X_{i}$ and the aggregator, $A(Y)$. Allowing both $A(Y)$ and $B_{i}(Y)$ to vary in $Y$ permits a rich variety of preferences to be represented. For example, income elasticities may be as large or small as one wishes, preferences need not be homothetic or identical, and there can be components of the vector $Y$ that are "goods" for some consumers and "bads" for others. Nevertheless, the assumption that preferences can be are represented in this form is restrictive. For instance with the special utility functions in our counterexamples for the Case of the Lazy Rotten Kids and the Case of the Controversial Nightlight there is not transferable utility. It follows from the Bergstrom-Cornes theorem that these preferences cannot be represented in the form (T3).

In the case of quasilinear utility, the highest utility possibility frontier for the family is reached when $I(Y)+\sum_{i} f_{i}(Y)$ is maximized. When utility takes the more general form, (T3), the highest utility possibility frontier is reached when $A(Y) I(Y)+\sum_{i} B_{i}(Y)$ is maximized. Consider the effects of an exogenous increase in family income from $I(Y)$ to $I(Y)+c$ for some constant $c$. In the case of quasilinear utility, the choice $Y$ that reaches the highest utility possibility frontier is unchanged by the income increase, while in the more general case, the change in family income will, in general, change the best choice of $Y$.

\section{Nightlights Revisited}

To illustrate the workings of transferable utility, let us examine the case of the Controversial Nightlight for cases where the private utility functions of the husband and wife take special forms that fall within the class expressed by (T3). The first case we look at is a simple example with transferable utility. Let the husband's private utility function be

$$
u_{h}\left(X_{h}, Y\right)=X_{h}+4 \ln (Y+1)
$$

and the wife's utility function be

$$
u_{w}\left(X_{w}, Y\right)=X_{w}-(Y+1)^{2} / 2 .
$$

Let the total amount of family income available to spend on the private good, $I$, be independent of the amount of nightlight, $Y$ that the husband consumes. Then for any choice of $Y$, the family utility possibility frontier is

$$
\left\{\left(u_{h}, u_{w}\right) \geq\left(\bar{u}_{h}, \bar{u}_{w}\right) \mid u_{h}+u_{w}=I+4 \ln (Y+1)-(Y+1)^{2}\right\}
$$

where $\left(\bar{u}_{h}, \bar{u}_{w}\right)=\left(4 \ln (Y+1),-(Y+1)^{2}\right)$. Suppose that the amount of nightlight is fixed at $Y$, but the husband decides the allocation of private goods in the family. Then he is able to choose his preferred point on the utility possibility frontier conditional on $Y$. Suppose as in our earlier discussion, that the husband is benevolent with a utility function 
$U_{h}\left(u_{h}, u_{w}\right)=u_{h} u_{w}^{a}$. Then he will choose to divide the family income so that the utility distribution in the family will be

$$
u_{w}=\frac{a}{1+a}\left(I+4 \ln (Y+1)-(Y+1)^{2}\right)
$$

and

$$
u_{h}=\frac{1}{1+a}\left(I+4 \ln (Y+1)-(Y+1)^{2}\right) .
$$

Knowing this, it will be in the interest of both the wife and the husband to choose $Y$ to maximize $I+4 \ln (Y+1)-(Y+1)^{2}$. Taking derivatives one finds that this is maximized when $Y=1$.

In the previous example, as must always be the case with quasilinear utility, the amount of nightlight chosen by the family was independent of income. But there are also some interesting examples with transferable utility where the amount of nightlight chosen depends on family income. Here is one such example. Suppose that the setup is as above except that the utility functions are

$$
u_{w}\left(X_{w}, Y\right)=(Y+1) X_{w}-\beta(Y+1)^{2}
$$

and

$$
u_{h}\left(X_{h}, Y\right)=(Y+1) X_{h}
$$

The utility possibility frontier is then

$$
\left\{\left(u_{h}, u_{w}\right) \geq\left(\bar{u}_{h}, \bar{u}_{w}\right) \mid u_{h}+u_{w}=(Y+1) I-\beta(Y+1)^{2}\right\}
$$

where $\left(\bar{u}_{h}, \bar{u}_{w}\right)=\left(0,-\beta(Y+1)^{2}\right)$. As before, let the amount of nightlight be fixed at $Y$, and let the husband decide the allocation of private goods in the family, given his utility function $U_{h}\left(u_{h}, u_{w}\right)=u_{h} u_{w}^{a}$. He will choose the allocation of private utilities,

$$
u_{w}=\frac{a}{1+a}\left((Y+1) I-\beta(Y+1)^{2}\right)
$$

and

$$
u_{h}=\frac{1}{1+a}\left((Y+1) I-\beta(Y+1)^{2}\right)
$$

Both family members will want to choose $Y$ so as to maximize $(Y+1) I-\beta(Y+1)^{2}$. This occurs when $Y=\frac{I}{2 \beta}-1$. In this case, the amount of $Y$ that both members of the household would want to supply is an increasing function of family income, but is independent of how that family income is distributed.

\section{What can be Done With Lazy Rotten Kids?}

We seek conditions that guarantee that there will be transferable utility in a family where both goods and leisure are consumption goods. Suppose that a family has $n$ members including a household head. Let family income be unearned income, $I_{0}$, plus the sum of the total earnings of household members. Let the earnings of household member $i$ be $w_{i} Y_{i}$, 
where $w_{i}$ is the "wage rate" that $i$ can command and where $Y_{i}$ is a measure of $i$ 's work effort. Each household member likes private consumption and is averse to work. Total family income will be $l(Y)=I_{0}+\sum_{i} w_{i} Y_{i}$. If there is to be transferable utility, then according to the Bergstrom-Cornes theorem, the private utility functions will have to be of the form $u_{i}\left(X_{i}, Y\right)=A(Y) X_{i}+B_{i}(Y)$ for each $i$. Recall that $Y$ is the vector $\left(Y_{1}, \ldots, Y_{n}\right)$ of work efforts by the $n$ family members. Suppose that each selfish family member dislikes working himself and does not care how hard other family members work if their efforts do not change his own consumption. Then it must be that for each $i$, the functions $A(Y)$ and $B_{i}(Y)$ depend only on $Y_{i}$ and not on $Y_{j}$ for $j \neq i$. Therefore, since $A(Y)$ is the same function for all $i$, it must be that $A(Y)$ is a constant. But this means that the utility function is of the quasilinear form. It follows that if family members are lazy and selfish, there is transferable utility conditional on levels of work effort only if preferences over consumption and work effort are quasilinear in leisure and consumption.

While it gives us an interesting example to play with, ${ }^{5}$ the assumption of quasilinear utility between consumption and work effort is not very appealing. With quasi-linear utility, an increase in unearned wealth has no effect on labor supply. ${ }^{6}$ Therefore it is worthwhile to see whether is a Rotten Kid Theorem for lazy rotten kids who are not quasilinear.

\section{Wages for (Nonquasilinear) Lazy Rotten Kids}

One way to get people to work is to pay wages. Although wages may be needed to elicit efficient amounts of labor, the Rotten Kid Theorem can still be applied to other activities that generate externalities in the family. We will show that there is a Rotten Kid Theorem that applies when family members get rewards for labor, but where the head of the household also makes lump sum gifts to all members of the household. For an appropriate class of preferences, it will remain the case that all family members desire the same levels of nonmarket activity by family members.

As in the usual theory of labor supply, it is useful to think of an individual who is paid a market wage and chooses leisure and consumption subject to a budget constraint. If this is done, there are two private goods of interest in the system-leisure and a consumption good. When will a family have transferable utility if there are two or more private goods? This is answered in a paper by Bergstrom and Varian (1985). The answer is (essentially) that there is transferable utility in a private goods economy if and only if indirect utility is of the Gorman polar form. ${ }^{\top}$ That is, whenever the indirect utility function of each person in the economy is of the form

$$
v_{i}\left(p, m_{i}\right)=\alpha(p) m_{i}+\beta_{i}(p)
$$

where $p$ is the price vector and $m_{i}$ is $i$ 's income. If there is a vector of public goods, $Y$, that affects utilities of the consumers, one can combine the Bergstrom-Varian result with the

\footnotetext{
s In fact in the field of industrial organization, almost everybody almost always assumes quasilinear utility.

6 With no income effects, there can be no backward bending labor supply curve and if this happens, what is left to teach in labor economics courses?

7 When preferences are of the Gorman polar form, income expansion curves of all consumers are straight lines for any price and are parallel for different consumers. Gorman (1961) proved that aggregate demand is independent of income distribution if and only if this is the case.
} 
Bergstrom-Cornes result, referred to earlier, to see that there will be transferable utility when

$$
u_{i}\left(Y, p, m_{i}\right)=\alpha(Y, p) m_{i}+\beta_{i}(Y, p)
$$

where the function $u_{i}($.$) represents person i$ 's preferences over environments in which the vector of nonmarket activities by household members is $Y$ and where $i$ 's income is $m_{i}$ and the vector of prices is $p$.

For this application, there is an extra complication. Usually, different family members will command different market wages. To handle this complication, one needs to generalize (W2) to allow different people to face different price vectors for private goods. Let $p^{i}$ be the price vector faced by $i$. ${ }^{8}$ Let us consider the case where $i$ 's preferences over price vectors and activity vectors are representable in the form

$$
u_{i}\left(Y, p^{i}, m_{i}\right)=A(Y) \alpha\left(p^{i}\right) m_{i}+\beta_{i}\left(Y, p^{i}\right) .
$$

Suppose further that the family budget constraint is

$$
\sum_{i} m_{i}=I(Y)
$$

If for each $i$, divide Equation (W3) through by $\alpha\left(p^{i}\right)$, sum the resulting expressions over the $i$ 's and substitute from (W4), to find that the utility possibility frontier is

$$
\left\{\left(u_{1}, \ldots, u_{n}\right) \geq\left(\bar{u}_{1}, \ldots, \bar{u}_{n}\right) \mid \sum_{i} \alpha\left(p^{i}\right)^{-1} u_{i}=A(Y) I(Y)+\sum_{i} \beta_{i}\left(Y, p^{i}\right)\right\}
$$

The effect of the vector $Y$ of nonmarket activities by is simply to induce a parallel shift of the utility possibility frontier. If the household allocation is chosen by a benevolent head, the different "weights", $\alpha\left(p^{i}\right)^{-1}$, on the utilities in (W5) act formally like the prices of the individual utilities, $u_{i}$. The nonmarket activities, $Y_{i}$ of family member $i$ affect only the right hand side of the household budget constraint. If the head of the household regards the utility of each household member as a normal good, then all household members will agree that the best choice of $Y$ for the family is the choice that maximizes $A(Y) I(Y)+$ $\sum_{i} \beta_{i}\left(Y, p^{i}\right)$. Therefore the Rotten $\mathrm{Kid}$ Theorem applies.

\section{Lazy, Noisy Rotten Kids}

Let us look at an example to see how our generalization of the Rotten Kid Theorem works. Suppose that members of a family like private consumption, and leisure. If family member $i$ spends the fraction $E_{i}$ of his day working, he can add $w_{i} E_{i}$ to family income. The family may also have some nonlabor income $I_{0}$. Each family member also likes to make noise, but is bothered by the noise made by others. Let $l_{i}=1-E_{i}$ be the fraction of the time that family member $i$ spends at leisure. Let $Y_{i}$ be the amount of noise that $i$ makes and

\footnotetext{
8 We are assuming that each family member is a price taker and that nothing that any family member chooses to do will alter any of the prices.
} 
let $Y=\left(Y_{1}, \ldots Y_{n}\right)$. Suppose that each member of the family has a direct utility function of the form

$$
u_{i}\left(X_{i}, l_{i}, Y\right)=A\left(\sum_{i} Y_{i}\right) l^{a} X_{i}^{1-a}+B_{i}\left(Y_{i}\right) .
$$

(Since noise is a nuisance but private goods are desirable, it must be that $A^{\prime}()<$.0 and $A()>$.0 on the relevant domain.) If family member $i$ receives nonlabor income $I_{i}$, then $i$ 's budget constraint will be $X_{i}=w_{i}\left(1-l_{i}\right)+I_{i}$. Equivalently, one can write

$$
X_{i}+w_{i} l_{i}=m_{i}
$$

where $m_{i}=w_{i}+I_{i}$ is $i$ 's full income. Since $i$ 's direct utility function is Cobb-Douglas in consumption and labor for a given vector $Y$ of noisemaking, it is not hard to show that $i$ 's indirect utility function is of the form,

$$
v_{i}=A\left(\sum_{i} Y_{i}\right) w_{i}^{-a} m_{i}+B_{i}\left(Y_{i}\right)
$$

The family budget constraint is

$$
\sum_{i} m_{i}=I_{0}+\sum_{i} w_{i}
$$

It follows from the second theorem of welfare economics that at any Pareto optimal allocation of resources in the family, there is an income $m_{i}$ for each $i$, such that $i$ 's consumption of goods and leisure maximizes his utility subject to the budget constraint (LNRK1). Therefore the family utility possibility frontier can be expressed in terms of the indirect utility functions, $v_{i}$. Summing the equations (LNRK3) over $i$ and using (LNRK4) one finds that this utility possibility frontier is

$$
\left\{\left(v_{1}, \ldots, v_{n}\right) \mid \sum_{i} w_{i}^{a} u_{i}=A\left(\sum_{i} Y_{i}\right)\left(I+\sum_{i} w_{i}\right)+\sum B_{i}\left(Y_{i}\right)\right\}
$$

The head of the household could achieve any allocation of utilities in the set (LNRK5) by making lump sum gifts to household members which would supplement the wages they earn. If the head of the household views the utilities of all household members as normal goods, then all selfish household members would be better off the larger is $A\left(\sum_{i} Y_{i}\right)\left(I_{0}+\right.$ $\left.\left.\sum_{i} w_{i}\right) \sum B_{i}\left(Y_{i}\right)\right)$. Therefore each selfish household member would agree that it is in his interest to contribute an amount of noise, $Y_{i}$, such that $A^{\prime}\left(\sum_{i} Y_{i}\right)\left(I_{0}+\sum_{i} w_{i}\right)=-B_{i}^{\prime}\left(Y_{i}\right)$. This is a Pareto optimal amount of noise.

\section{A Rotten Kid Theorem Without (Necessarily) Rotten Kids}

The discussion so far has concerned a family with only one unselfish member, the head. Let us now consider the more reasonable case where several family members are concerned about each others' welfare. Becker calls this the case of "reciprocal altruism" and offers some useful suggestions of how the Rotten Kid Theorem would extend to this case.

There are at least two reasonable ways of modelling consumers who are benevolent toward each other. The first way is to start with individual preferences over allocations 
as the fundamental concept. Let a household allocation be represented as $\left(X_{1}, \ldots, X_{n}, Y\right)$ where $X_{i}$ is the vector of private goods consumed by family member $i$ and $Y$ is a vector of household public goods and of externality generating activities by family members. Suppose that the preferences of any individual over allocations are weakly separable between individuals and respond benevolently to the level of private preferences of each $i$. Then $i$ 's preferences can be represented by a utility function of the form

$$
U_{i}\left(u_{1}\left(X_{1}, Y\right), \ldots, \dot{u}_{n}\left(X_{n}, Y\right)\right)
$$

where $u_{i}\left(X_{i}, Y\right)$ represents $i$ 's preferences over alternative commodity bundles in which the $u_{j}$ for $j \neq i$ are held constant. The preferences represented by $u_{i}$, we will call private preferences, the preferences represented by $U_{i}$, we will call $i$ 's total preferences. If all family members are nonmalevolent, then $U_{i}$ is a nondecreasing function of each of the $u_{j}$ 's. If there is a household head who decides the allocation of resources in the family, and if the private utility of each family member is a normal good for the head, then our previous analysis applies without modification. Anything that shifts the private utility possibility frontier outward in a parallel fashion, will lead the head to choose an outcome with higher private utilities for everyone. But since everyone is assumed to be nonmalevolent, it must be that if private utility, $u_{i}$, increases for everyone, then so will total utility $U_{i}$. Therefore The Rotten Kid Theorem will apply.

There is a possible snag here. What right have we to assume, in a family with complicated reciprocal entanglements of benevolence, that family members' private utilities will be "normal goods" for the head of the household? Admittedly, economists are not timid about making assumptions, but at least in microeconomics it is bad form to make strong assumptions without knowing what they mean. The matter deserves further analysis.

It is helpful to look at a second way of modelling benevolence. Suppose that each consumer's total utility, $U_{i}(X, Y)$ is determined by his private utility, $u_{i}\left(X_{i}, Y\right)$ and by the total utilities, $U_{j}(X, Y)$ of other family members. Then the utility function of family member $i$ is written:

$$
U_{i}=U_{i}\left(U_{1}(X, Y), \ldots, u_{i}\left(X_{i}, Y\right), \ldots, U_{n}(X, Y)\right)
$$

Let $A$ be the $n \times n$ matrix with zeroes on the diagonal and with $\boldsymbol{A}_{i j}=\partial U_{i} / \partial U_{j}$ for $i \neq j$. According to the implicit function theorem (given sufficient smoothness), if $I-A$ is nonsingular, the system of equations the system of equations (W2) locally determines a system of equations of the form (W1). With assumptions a little stronger than the assumption that $I-A$ is nonsingular over the relevant domain, (see Nikaido (19??)) the system of equations (W2) has a global inverse of the form (W1). When this is the case, we know that representabily in either form implies representability in the other form and we even have a recipe for moving from one form of representation to the other.

Although preferences can be represented in the form (W1), it may be more difficult to decide what is reasonable to assume about these utility functions than to decide what is reasonable to assume about utility functions in the form (W2). For example, one may be willing to assume that the total utilities $U_{j}$ are normal*goods for consumer $i$. Then an increase in household wealth would make consumer $i$ want to give all of the other $i$ 's increases in total utility. But this does not necessarily imply that private utilities, $u_{i}$, are also normal goods. 
There is a nice class of cases in which the assumption that total utilities, $U_{i}$ are normal goods implies that private utilities are normal goods as well and where transferable utility in private utilities implies transferable utility in total utilities. The case is this. Suppose that each $i$ has preferences representable in the additively separable form,

$$
U_{i}=u_{i}+\sum_{j \neq i} A_{i j} U_{j}
$$

where $A_{i j} \geq 0$ for all $i$ and $j$. Suppose further that the row sums of the matrix $I-A$ are all positive. Nonnegativity of the $A_{i j}$ 's simply means nonmalevolence. Positivity of the row sums means that individuals are "partially selfish" in the sense that they weigh their own utilities more heavily than the sum of the weights they place on others. Under these assumptions, the theory of dominant diagonal matrices applies and tells us that the matrix $B=(I-A)^{-1}$ exists and is nonnegative in every entry. It follows from (W3), that

$$
U_{i}=\sum_{j} B_{i j} u_{j}
$$

for all $i$.

Equation (W4) is just enough to allow us to apply the Rotten Kid Theorem bodily. Since the $U_{i}$ 's are related by a linear transformation of the $u_{i}$ 's, the utility possibility frontier expressed in terms of the $U_{i}$ 's will be a simplex if and only if the utility possibility frontier expressed in terms of the $u_{i}$ 's is a simplex. Furthermore an outward shift in the latter frontier will imply an outward shift in the former. It follows that if there is transferable utility in the $u_{i}^{\prime}$ s then there will be transferable utility in the $U_{i}$ 's. Therefore if the head of the household regards the $U_{i}^{\prime}$ s as normal goods, the Rotten Kid Theorem applies.

\section{Extensions and Pontifications}

I have claimed that the answer to "When does the Rotten Kid Theorem apply to a household?" is essentially "When the household has is transferable utility." Fortunately for the Rotten Kid Theorem, it happens that transferable utility in a household extends beyond the case of a single good and beyond the case of quasi-linear preferences to a more general and interesting class of preferences and technologies. But unfortunately for the Rotten Kid Theorem, this is still quite a restricted class.

This paper has studied conditions under which the household utility possibility frontier is a simplex which is shifted inward or outward in parallel fashion by different choices of nonmarket activities. In these cases, the Rotten Kid Theorem applies if the utilities of all household members are normal goods for the household head. It is fair to ask whether, there might be other interesting cases where the Rotten Kid Theorem applies. For example, consider "curved" utility possibility frontiers that shift outward "uniformly" in response to changes in the nonmarket activities of family members. One might want to compensate for weaker assumptions about the utility possibility frontier by making stronger assumptions about the preferences of the household head. One way to do this would be to suppose that the nonmarket activities of family members resulted in homothetic shifts of the nonlinear utility possibility frontier and that the head of the household has homothetic preferences 
in the private utilities of family members. Perhaps some more interesting generalizations lie in this direction. But $I$ have not explored them.

The Rotten Kid theorem is a contribution to the theory of information and incentives. It is therefore interesting to consider explicitly the informational requirements of this theorem. It is helpful to distinguish behavior revelation from preference revelation. When the Rotten Kid theorem applies, the head of the family does not need to observe the vector $Y$ of externality generating activities by household members. Everybody in the family has an incentive to do the "right thing" even though behavior is not publically revealed. Of course there is remains the "team theory" problem of coordination between people seeking to maximize the same thing. But, even where it applies, the Rotten Kid theorem in general does not "solve" the preference revelation problem. Except in the trivial case where there is only one good, all household members need to know something about each others' preferences in order to know what the appropriate choice of $Y$ is. ${ }^{\circ}$ This is evident, for example, in the case of quasilinear utility where all family members want to choose $Y$ to maximize the function, $I(Y)+\sum_{i} f_{i}(Y)$. But the $f_{i}(Y)$ 's are the individuals' willingness-to-pay for the vector $Y$.

In a household, perhaps the preference revelation problem is not so severe as the behavior revelation problem. Because family members interact closely and repeatedly, it is arguable that eventually family members know each others' preferences all too well. On the other hand, if it is in their interest to conceal their actions, family members may be able to do so at least occasionally. Still it would be interesting to study the preference revelation problem in an environment where the Rotten Kid Theorem applies. It is worth noticing that the Groves-Clarke mechanism (Groves and Loeb (1975), Clarke (1971), which makes honest preference revelation a dominant strategy, applies precisely when there is transferable utility. ${ }^{10}$

The kinship between the Rotten Kid theorem and the Coase theorem is intriguing. $\Lambda$ s Cooter (1982) points out, Coase, in his classic article, steadfastly refrained from stating a general "theorem" underlying his examples. Quite wisely, it seems, Coase chose to present the profession with a "Coase insight" and left formal details to be worked out by others. Statements of "the Coase theorem" appear in the works of others. For example, Zerbe (1976) proposes the following statement of the Coase theorem.

"In a world of perfect competition, perfect information, and zero transaction costs, the allocation of resources will be efficient and invariant with respect to legal laws of liability"

This statement of the "Coase theorem" has two distinct claims. One is that "in the absence of transactions costs and with perfect information", private bargaining will lead to an efficient outcome regardless of the legal assignment of property rights. The second is that the "allocation of resources" will be it invariant to the assignment of property rights. The general validity of both claims has been much disputed in the literature. ${ }^{11}$. There is little dispute, however, that Coase's examples have profoundly improved the profession's understanding of the possibilities for private "bargaining the shadow of the law".

\footnotetext{
- In fact, in the model where there is just one good, it is implicitly assumed that everybody knows every thing about everyone's preferences. There just isn't very much to know.

10 In the original presentions the mechanism was applied only to the case of quasilinear utility. Bergstrom and Cornes (1983) extended the results to the case where utility functions are of the form $A(Y) X_{i}+B_{i}(Y)$.

11 See Cooter (1982) for a good discussion
} 
The Coasian clain of "invariance of resource allocation with respect to the assignment of property rights" has been shown not to hold in generality. It is very easy to produce examples where the Pareto efficient level of an externality-generating activity depends on which point on the utility possibility frontier is selected. 12 But the point on the utility possibility frontier that is selected depends on the initial allocation of property rights. As it turns out, the conditions that allow the Rotten Kid Theorem to be salvaged are precisely the conditions needed for "Coasian invariance" to obtain within the family. The result that the Rotten Kid Theorem implies Coasian invariance is almost immediate from the statements of the two results. In their 1983 paper, Bergstrom and Cornes showed that the assumption that utility functions take the form $U_{i}\left(X_{i}, Y\right)=A(Y) X_{i}+B_{i}(Y)$ is both necessary and sufficient for the Pareto optimal amount $Y$ of public goods to be independent of income distribution and that this assumption is also equivalent to the existence of transferable utility in an economy with one private and one public good.

Thus we see that the two Chicago siblings prosper in similar environments. There is, I think another and perhaps more important family resemblance. Each "theorem" is at least as useful as a heuristic generator of insight as it is as a formal proposition. Anyone who only reads presentations of the "Coase Theorem" without reading Coase's rich insightful discussion of examples has missed the best of the story. Much the same can be said of the "Rotten Kid Theorem". The richness of insight that Becker has to offer about the economics of the family is only partially captured in formal analysis of Rotten $\mathrm{Kid}$ theorems. Many nice insights into the economics of the family and the economics of incentives that have escaped formal treatment in this paper are to be found in Becker's discussion and examples in the Treatise on the Family and in his 1974 article.

12 One simple instance is the example presented in this paper in the Case of the Controversial Nightlight. 


\section{Bibliography}

Becker G. (1974) "A Theory of Social Interactions," Journal of Political Economy, 82, 1063-1094.

Becker G. (1981) A Treatise on the Family. Cambridge, Mass.: Harvard University Press.

Bergstrom T., and Cornes, R. (1983) "Independence of Allocative Efficiency from Distribution in the Theory of Public Goods," Econometrica, 51, 1753-1765..

Bergstrom T., and Cornes, R. (1981) "Gorman and Musgrave are Dual-An Antipodean Theorem on Public Goods," Economic Letters, , 371-378.

Bergstrom T., and Varian H. (1985) "When do Market Games Have Transferable Utility," Journal of Economic Theory, 35, 222-233.

Cooter, R. (1982) "The Cost of Coase," Journal of Legal Studies, XI, 1-33.

Coase, R. (1960) "The Problem of Social Cost," Journal of Law and Economics, 1, 1-44.

Clarke, E. H. (1971) "Multipart Pricing of Public Goods," Public Choice, 5, 17-33.

Gorman, W.M. (1961) "On a Class of Preference Fields," Metroeconomica, 13, 53-56.

Groves, T. and Loeb, M. (1975) "Incentives and Public Inputs," Journal of Public Economics, 4, 211-226.

Marschak, J., and Radner, R. (1972) Economic Theory of Teams. New Haven: Yale University Press.

Nikaido, H. (1968) Convex Structures and Economic Theory. New York: Academic Press.

Zerbe, R. (1976) "The Problem of Social Cost: Fifteen Years Later," in Theory and Measurement of Externalities, ed. Steven Lin. New York: Academic Press. 


\section{Recent CREST Working Papers}

87-1: Jeffrey K. MacKie-Mason, "Nonlinear Taxation of Risky Assets and Investment, With Application to Mining" September, 1984.

87-2: Jeffrey K. MacKie-Mason, "Sequential Decision Problems and Asymmetric Information" September, 1985.

87-3: Michelle J. White, “Contract Breach and Contract Discharge due to Impossibility: A Unified Theory" July 29, 1987.

87-4: Ted Bergstrom, "Systems of Benevolent Utility Interdependence” May 19, 1987.

87-5: Ted Bergstrom, "A Fresh Look at the Rotten Kid Theorem-and Other Household Mysteries" November, 1986.

87-6: Michelle J. White, “The Corporate Bankruptcy Decision” July, 1987.

87-7: Michelle J. White, "Location Choice and Commuting Behavior in Cities with Decentralized Employment" July, 1987.

87-8: Lawrence E. Blume and David Easley, "Implementation of Walrasian Expectations Equilibria" December, 1985.

87-9: Lawrence E. Blume, "Lexiocographic Refinements of Nash Equilibrium” April, 1986.

87-10: David Lam, "Lorenz Curves, Inequality, and Social Welfare Under Changing Population Composition" June 16, 1987.

87-11: Mark Bagnoli and Naveen Khanna, "Equilibrium with Debt and Equity Financing of New Projects: Why More Equity Financing Occurs When Stock Prices are High" June, 1987.

87-12: Mark Bagnoli and Barton L. Lipman, "Provision of Public Goods: Fully Implementing the Core through Private Contributions" March, 1987.

87-13: Mark Bagnoli and Barton L. Lipman, "Successful Takeovers without Exclusion" August, 1987.

87-14: Mark Bagnoli and Michael McKee, "Controlling the Game: Political Sponsors and Bureaus" May, 1987.

87-15: Mark Bagnoli and Michael McKee, "Can the Private Provision of Public Goods be Efficient?-Some Experimental Evidence" March, 1987.

87-16: Mark Bagnoli, "Non-Market Clearing Prices in a Dynamic Oligopoly with Incomplete Information" January, 1986.

87-17: John Laitner, “Bequests, Gifts, and Social Security” February 28, 1986.

87-18: John Laitner, "Dynamic Determinacy and the Existence of Sunspot Equilibria” May 12, 1986.

87-19: David Lam, “Does a Uniform Age Distribution Minimize Lifetime Wages?” August 12, 1987.

87-20: David Lam, “Assortative Mating with Household Public Goods" April, 1987.

87-21: Jeffrey A. Miron and Stephen P. Zeldes, "Production, Sales, and the Change in Inventories: An Identity that Doesn't Add Up" June 1987.

87-22: Jeffrey A. Miron and Stephen P. Zeldes, "Seasonality, Cost Shocks, and the Production Smoothing Model of Inventories" December, 1986.

87-23: Hal R. Varian, "Differences of Opinion in Financial Markets" March, 1985.

87-24: Roger H. Gordon and Hal R. Varian, "Taxation of Asset Income in the Presence of a World Securities Market" August, 1986. 
87-25: Hal R. Varian, "Measuring the Deadweight Casts of DUP and Rent Seeking Activities" November, 1982.

87-26: Hal R. Varian, “Price Discrimination” January, 1987.

87-27: Roger H. Gordon and Hal R. Varian, "Intergenerational Risk Sharing" October, 1985.

87-28: Hal R. Varian, “Three Papers on Revealed Preference" August, 1987.

87-29: Hal R. Varian, "Optimal Tariffs and Financial Asséts" April, 1987.

87-30: Jonathan Cave and Stephen W. Salant, "Cartels That Vote: Agricultural Marketing Boards and Induced Voting Behavior" August, 1987.

87-31: Stephen W. Salant and Donald H. Negri, "Pastures of Plenty: When is the Standard Analysis of Common Property Extraction Under Free Access Incorrect?" July 10, 1987.

87-32: Stephen W. Salant, “When is Inducing Self-Selection Sub- optimal for a Monopolist?" February, 1987.

87-33: Stephen W. Salant, “Treble Damage Awards in Private Lawsuits for Price-Fixing” August, 1987.

87-34: Stephen W. Salant and Roy Danchick, "Air Force Academy Attrition: A New Perspective on the College Dropout Problem" August, 1987.

87-35: Stephen W. Salant and Eban Goodstein, "Committee Voting Under Alternative Procedures and Preferences: An Experimental Analysis" April 20, 1987.

87-36: Robert B. Barsky and Jeffrey A. Miron, "The Seasonal Cycle and the Business Cycle" June, 1987.

87-37: Robert B. Barsky, N. Gregory Mankiw, Jeffrey A. Miron and David N. Weil, "The Worldwide Change in the Behavior of Interest Rates and Prices in 1914" July, 1987.

87-38: Jeffrey K. MacKie-Mason, “Taxes, Information and Corporate Financing Choices” April 1986. 


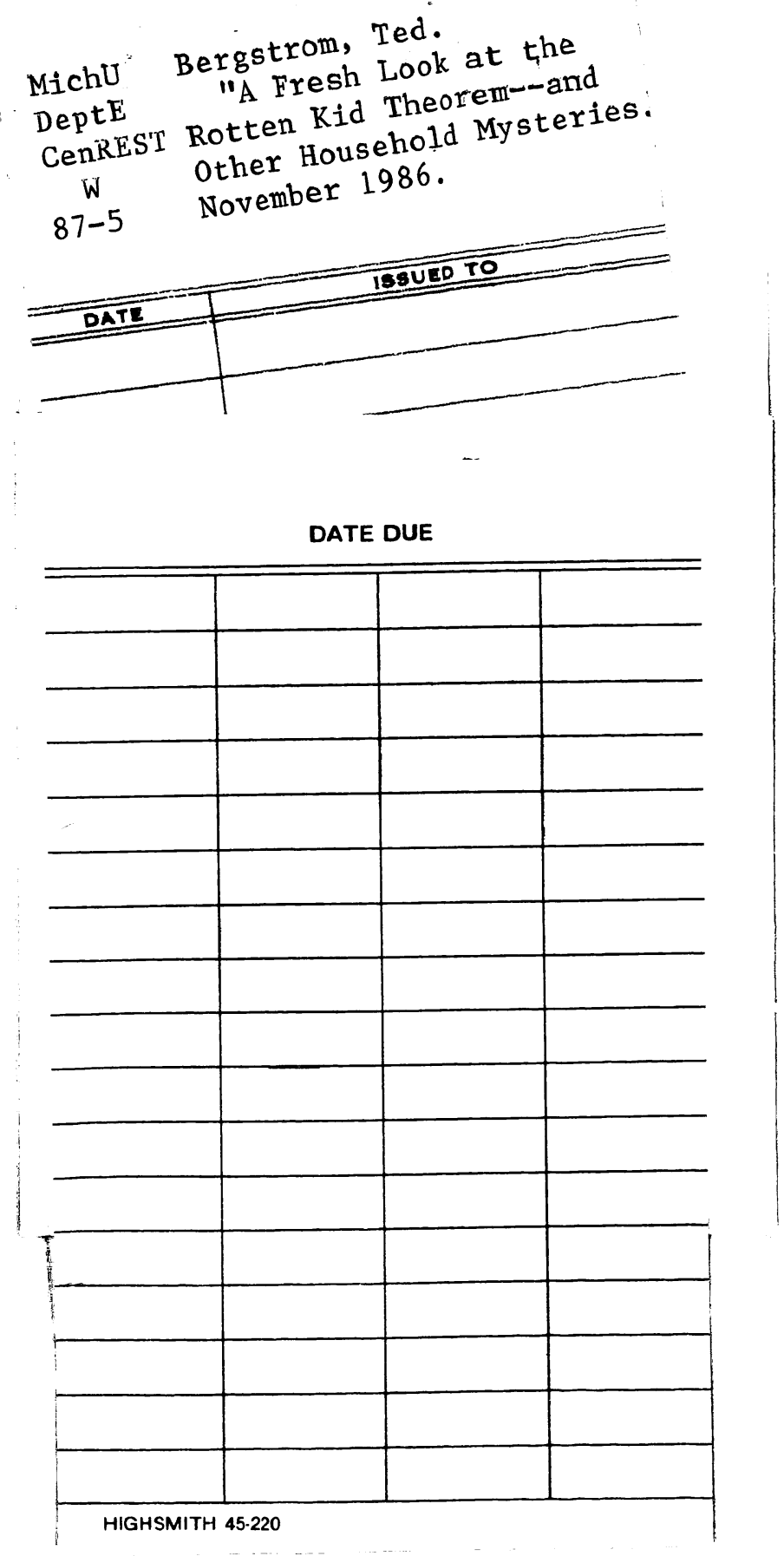


